\title{
Antagonism of Trichoderma harzianum ETS 323 on Botrytis cinerea Mycelium in Culture Conditions
}

\author{
Chi-Hua Cheng, Chia-Ann Yang, and Kou-Cheng Peng
}

First and third authors: Institute of Biotechnology, National Dong-Hwa University, Hualien 97401, Taiwan, R.O.C.; and second author: Institute of Medical Science, Tzu Chi University, Hualien 97004, Taiwan, R.O.C. Accepted for publication 15 June 2012.

\section{ABSTRACT}

Cheng, C.-H., Yang, C.-A., and Peng, K.-C. 2012. Antagonism of Trichoderma harzianum ETS 323 on Botrytis cinerea mycelium in culture conditions. Phytopathology 102:1054-1063.

Previous studies have shown that the extracellular proteins of Trichoderma harzianum ETS 323 grown in the presence of deactivated Botrytis cinerea in culture include a putative L-amino acid oxidase and have suggested the involvement of this enzyme in the antagonistic mechanism. Here, we hypothesized that the mycoparasitic process of Trichoderma spp. against $B$. cinerea involves two steps; that is, an initial hyphal coiling stage and a subsequent hyphal coiling stage, with different coiling rates. The two-step antagonism of T. harzianum ETS 323 against $B$. cinerea during the mycoparasitic process in culture was evaluated using a biexponential equation. In addition, an L-amino acid oxidase (Th-L-AAO) was identified from T. harzianum ETS 323. The secretion of Th-L-AAO was increased when $T$. harzianum ETS 323 was grown with deactivated hyphae of $B$. cinerea. Moreover, in vitro assays indicated that Th-L-AAO effectively inhibited $B$. cinerea hyphal growth, caused cytosolic vacuolization in the hyphae, and led to hyphal lysis. Th-L-AAO also showed disease control against the development of $B$. cinerea on postharvest apple fruit and tobacco leaves. Furthermore, an apoptosis-like response, including the generation of reactive oxygen species, was observed in $B$. cinerea after treatment with Th-L-AAO, suggesting that Th-L-AAO triggers programmed cell death in $B$. cinerea. This may be associated with the two-step antagonism of T. harzianum ETS 323 against B. cinerea.
Botrytis cinerea is a necrotrophic fungus associated with $>200$ host plants (37) and is the causal agent of gray mold disease, which can affect fruit (9), vegetable, and ornamental crops (41). Because of its impact on such a broad range of hosts, $B$. cinerea is one of the most important plant pathogens worldwide (47). Previous studies have reported that $B$. cinerea under culture conditions kills host cells by producing toxins (e.g., oxalic acid and phytotoxic metabolites) and plant cell-wall-degrading enzymes. B. cinerea has also been reported to penetrate the host tissue by either hyphae or appressoria through stomata or wounds $(14,19,20,38)$ but the appressorium is not considered capable of penetrating plant tissue by physical pressure alone $(31,37)$.

Fungal strains of the genus Trichoderma are important biocontrol agents used as biopesticides worldwide (4), and are attractive biocontrol agents for phytopathogens such as B. cinerea, Fusarium spp., Pythium spp., Rhizoctonia solani, and Sclerotium rolfsii $(8,34)$. Trichoderma spp. use several biocontrol mechanisms, including mycoparasitism through the dense coiling of hyphae around the host pathogen, the secretion of antibiotics such as enzymes and secondary metabolites, rhizosphere modification, competition for resources and space, and promotion of plant growth and defense mechanisms $(4,7,36,48)$.

L-Amino acid oxidases (L-amino acid:oxygen oxidoreductase [deaminating], EC 1.4.3.2; L-AAOs) catalyze the oxidative deamination of L-amino acids and produce the corresponding $\alpha$-keto acids, as well as ammonia and hydrogen peroxide $\left(\mathrm{H}_{2} \mathrm{O}_{2}\right)(13,30)$. L-AAO occurs widely in snakes $(39,40)$, bacteria $(22)$, and algae

Corresponding author: K. C. Peng; E-mail address: kcpeng@mail.ndhu.edu.tw

* The $e$-Xtra logo stands for "electronic extra" and indicates that the online version contains supplemental material not available in the print edition.

http://dx.doi.org/10.1094/PHYTO-11-11-0315

(C) 2012 The American Phytopathological Society
(46). Because of the cytotoxic effects of this enzyme on various cells, including cancer cells (1), platelets (44), and microorganisms (49), L-AAO has become the focus of research in the fields of biochemistry, physiology, and medicine. However, a previous proteomic study revealed the presence of a putative L-AAO in the secreted proteins of Trichoderma harzianum ETS 323 grown in a medium containing deactivated $B$. cinerea hyphae (50).

A more detailed understanding of the mycoparasitic mechanisms of T. harzianum, as well as the effect of L-AAO secretion on the antagonism of $T$. harzianum against $B$. cinerea, would produce benefits in the application of Trichoderma spp. as a biocontrol agent. In the mycoparasitic process of Trichoderma spp., the hyphae of the Trichoderma sp. encircle and coil around the hyphae of the host pathogen (a physical process defined as the "hyphal coiling" of Trichoderma spp.) (24). Once the host is encoiled, Trichoderma spp. secrete lytic enzymes such as glucanase and chitinase to penetrate the host and then use the host cellular contents as a source of nutrients $(11,25)$. Here, we assume that the host pathogen may have a defense response to the presence of the initial hyphal coiling of Trichoderma spp. in the early stages of the mycoparasitic process. Thus, an antagonism between these two fungi may occur through the secretion of extracellular proteins. Moreover, the process of hyphal coiling in Trichoderma spp. may become impeded because of the resistance response of the host pathogen. Therefore, we suggest that the hyphal coiling of Trichoderma spp. may undergo a slow phase at a later stage in the continuing mycoparasitic interaction with the host, as the defense response of the host pathogen is attenuated by the secreted proteins of Trichoderma spp. Considering these possibilities, we believe that the hyphal coiling process of Trichoderma spp. may involve an initial coiling stage and a subsequent coiling stage via different rates of hyphal coiling and suggest that the mycoparasitic process of Trichoderma spp. may be split into more than one antagonistic step. Therefore, the aim of this work was to ascertain the effect of $T$. harzianum 
L-AAO on the hyphal growth of $B$. cinerea and to present a conceptual framework linking this effect to the mycoparasitic activity of the fungus.

\section{MATERIALS AND METHODS}

Chemical materials. All chemicals were purchased from Sigma-Aldrich (St. Louis. Potato dextrose agar (PDA) and potato dextrose broth (PDB) were obtained from Difco (Franklin Lakes, New Jersey). Number 1 filter paper was obtained from Advantec Toyo Kaisha (Tokyo). Mito-Capture was purchased from BioVision (Palo Alto, CA).

Cultivation of $\boldsymbol{T}$. harzianum ETS 323 and deactivated $\boldsymbol{B}$. cinerea. T. harzianum ETS 323 was cultivated following the method described by Yang et al. (50). In brief, T. harzianum was grown on PDA-coated plates at $25^{\circ} \mathrm{C}$ for 7 days. Sterile water ( $2 \mathrm{ml}$ ) was added to flush the plates of T. harzianum ETS 323. Conidia $\left(\approx 10^{6} \mathrm{ml}^{-1}\right)$ were collected and inoculated in $250 \mathrm{ml}$ of minimal medium nourished with $1 \%(\mathrm{wt} / \mathrm{vol})$ glucose in a $500-\mathrm{ml}$ Erlenmeyer flask; the minimal medium contained $\left(\mathrm{NH}_{4}\right)_{2} \mathrm{SO}_{4}$ at $1.4 \mathrm{~g} \mathrm{liter}^{-1}, \mathrm{KH}_{2} \mathrm{PO}_{4}$ at $2.0 \mathrm{~g} \mathrm{liter}^{-1}, \mathrm{NaH}_{2} \mathrm{PO}_{4}$ at $6.9 \mathrm{~g} \mathrm{liter}^{-1}$, $\mathrm{MgSO}_{4} \cdot 7 \mathrm{H}_{2} \mathrm{O}$ at $0.3 \mathrm{~g} \mathrm{liter}^{-1}$, peptone at $1.0 \mathrm{~g} \mathrm{liter}^{-1}$, and urea $\left(\mathrm{pH} \mathrm{5.0)}\right.$ at $0.3 \mathrm{~g} \mathrm{liter}^{-1}$. The cultures were grown at $22^{\circ} \mathrm{C}$ in an incubator with a shaker at $180 \mathrm{rpm}$ for 7 days. The mycelia were then collected by filtration through a cheesecloth, washed three times with sterile Milli-Q (18.2 M $\Omega$ ) water, and inoculated in fresh minimal medium containing $0.5 \%$ (wt/vol) glucose and $0.5 \%$ (wt/vol) deactivated $B$. cinerea hyphae. The $B$. cinerea hyphae had been cultivated and then deactivated as previously described (50). These cultures were grown for another 5 days at $22^{\circ} \mathrm{C}$ in the incubator with the shaker at $180 \mathrm{rpm}$. The culture medium was collected by filtration through a cheesecloth and number 1 filter paper, and stored at $-20^{\circ} \mathrm{C}$ until use.

Antagonistic assay with $T$. harzianum ETS 323 and $B$. cinerea. A thin layer of PDA was spread on clean, sterile glass microscope slides in the center of sterile culture plates. The medium was inoculated with 4-mm-diameter mycelia of both $T$. harzianum ETS 323 (accession number BCRC 930081; Bioresource Collection and Research Center, Food Industry Research and Development Institute, Hsinchu, Taiwan) and B. cinerea cut from the growing edges of 5-day-old cultures at the opposing site, and then further incubated for 5 days at $25^{\circ} \mathrm{C}$. The glass slides were stained with lactophenol blue (Fluka Chemie, Buchs, Switzerland) to improve the visibility of the hyphae, then observed under a light microscope (IX70; Olympus, Tokyo) with an attached camera (Olympus SC35). The hyphal interactions between the opposing colonies were photographed every $24 \mathrm{~h}$.

Kinetics of the antagonistic effect of $T$. harzianum ETS 323 against $\boldsymbol{B}$. cinerea. $T$. harzianum is a mycoparasite that acts antagonistically by coiling its hyphae around the host hyphae (e.g., B. cinerea). The frequency of the hyphal coiling of $T$. harzianum ETS 323 against $B$. cinerea was plotted against time and was defined as the number of coiling $T$. harzianum hyphae per square millimeter on $B$. cinerea hyphae (Fig. 1). Here, we propose that the mycoparasitism of $T$. harzianum against $B$. cinerea involves a two-step antagonism (initial hyphal coiling and then continued hyphal coiling), as described here by equation 1a. Therefore, biphasic kinetics $(3,17)$ may occur in a time course of the hyphal coiling of $T$. harzianum ETS 323 against $B$. cinerea. This biphasic kinetics best fits the biexponential equation 1b. Biphasic kinetics was observed in the exponential growth phase (Fig. 1), with two rates for the hyphal coiling (i.e., $k_{\text {obs.1 }}$ and $k_{\text {obs. } 2) \text {. }}$

$$
\begin{aligned}
& <\text { coiling > < more coiling > } \\
& T+B \underset{\text { step } 1}{\stackrel{k_{\text {obs. } 1}}{\longrightarrow}} T B_{1} \stackrel{k_{\text {obs. } 2}}{\stackrel{\text { step } 2}{\longrightarrow}} T B_{2}
\end{aligned}
$$

$$
F(t)=F_{1}\left(1-e^{-k_{o b s .1 \cdot t}}\right)+F_{2}\left(1-e^{-k_{o b s .2 \cdot t}}\right)
$$

where $T$ and $B$ are $T$. harzianum ETS 323 and $B$. cinerea, respectively, and $T B_{1}$ and $T B_{2}$ are the mycoparasitic states of $T$. harzianum against $B$. cinerea via hyphal coiling after steps 1 and 2 of the antagonism, respectively. The designations coiling and more coiling are the initial and further hyphal coiling of $T$. harzianum ETS 323 against $B$. cinerea for rates $k_{\text {obs.1 }}$ and $k_{\text {obs. } 2 \text {, }}$ respectively. We suggest that $T B_{2}$ is the state of the final extent of $T$. harzianum coiling against $B$. cinerea. For equation $1 \mathrm{~b}$, the independent variable is $t$, the number of days after hyphal contact. $F_{(t)}$ is the dependent variable and indicates the time-dependent coiling frequency. $F_{1}$ and $F_{2}$ are the amplitude of the coiling frequency after steps 1 and 2 of the antagonism, respectively. The value of $F_{1}+F_{2}$ is the maximum hyphal coiling frequency of $T$. harzianum against $B$. cinerea. Amplitudes were normalized to the maximum hyphal coiling frequency. The $k_{\mathrm{obs} .1}$ and $k_{\mathrm{obs} .2}$ are the rate constants of hyphal coiling at steps 1 and 2 of the antagonism, respectively. The kinetic data were fitted to biexponential functions using the software Origin 7.0 (MicroCal, Northampton, MA) implementation of a nonlinear least-squares-fitting algorithm. The initial estimates for $F_{1}, F_{2}, k_{\text {obs.1 }}$, and $k_{\text {obs.2 }}$ were 1 for all parameters.

Purification of putative Th-L-AAO. The extracellular protein extract from the culture medium was concentrated with an Amicon Ultra-4 centrifugal filter unit (3-kDa molecular mass cutoff; Millipore, Billerica, MA) and subsequently applied to the two steps of purification by ÄKTAprime plus 100 FPLC (Healthcare Bio-Sciences, Piscataway, NJ). The protein-containing extract was loaded onto a ConA-Sepharose column ( $5 \mathrm{ml}$; GE Healthcare Bio-Sciences), which was washed with a buffer containing $1 \mathrm{mM}$ $\mathrm{CaCl}_{2}, 1 \mathrm{mM} \mathrm{MnCl}, 0.5 \mathrm{M} \mathrm{NaCl}$, and 0.02 M Tris-HCl (pH 7.4),

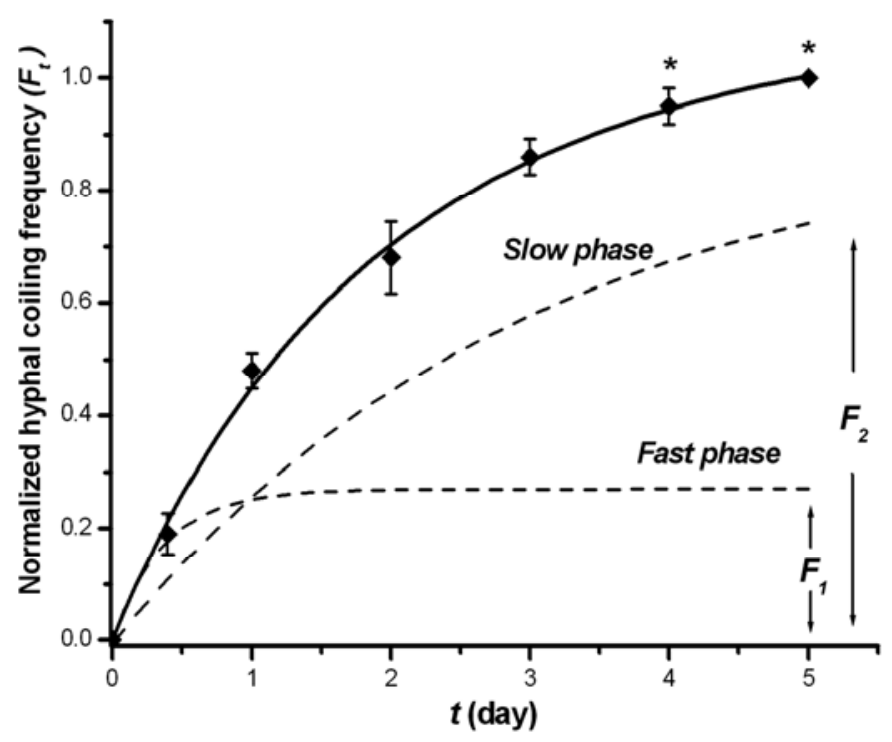

Fig. 1. Hyphal coiling frequency of Trichoderma harzianum ETS 323 against Botrytis cinerea was evaluated by microscopy in the interaction zone between T. harzianum and B. cinerea. Coiling frequency was defined as coiling number per square millimeter. The asterisk indicates hyphal lysis of $B$. cinerea. For allowing a direct comparison of the percentage of the amount of hyphal coiling, the value representing the final extent of the coiling frequency has been normalized to 1 . Hyphal coiling kinetics was fitted to the biexponential equation $1 \mathrm{~b}$. The nonlinear fit curve with $R^{2}$ was 0.99 . Broken lines reflect the theoretical decomposition of the time-dependent coiling of $T$. harzianum against $B$. cinerea into two phases (fast phase and slow phase). $F_{1}$ and $F_{2}$ are the amplitude of the coiling frequency after steps 1 and 2, respectively, of the antagonism of $T$. harzianum against $B$. cinerea (see Materials and Methods). Values are the means of three independent experiments. Bars represent the standard error from the mean $(n=3)$. 
then eluted with a linear gradient of methyl- $\alpha$-D-mannopyranoside $(0$ to $0.5 \mathrm{M})$ in $0.02 \mathrm{M}$ Tris- $\mathrm{HCl}$ buffer $(\mathrm{pH} 7.4)$ containing $0.5 \mathrm{M} \mathrm{NaCl}$ at a flow rate of $1 \mathrm{ml} \mathrm{min}^{-1}$. Glycoprotein fractions were collected and concentrated by ultrafiltration, and subjected to a Superdex HR 75 10/30 column (Amersham Pharmacia Biotech, Uppsala, Sweden). This glycoprotein fraction column was eluted with $20 \mathrm{mM}$ sodium phosphate buffer ( $\mathrm{pH}$ 7.4) at a flow rate of $0.2 \mathrm{ml} \mathrm{min}{ }^{-1}$. The following protein standards were used for calibration: myoglobin (17 kDa), bovine serum albumin $(67 \mathrm{kDa})$, and human immunoglobulin $(150 \mathrm{kDa})$. All chromatographic steps were monitored at $280 \mathrm{~nm}$ and performed at $25^{\circ} \mathrm{C}$.

Analysis of Th-L-AAO secretion by $T$. harzianum ETS 323. The activity of Th-L-AAO was determined by enzyme-coupled assay $(2,27,32,45)$. In brief, L-Phe and D-Phe were used as substrates for Th-L-AAO, and were added to a 200- $\mu$ l reaction mixture containing $4.7 \mathrm{U}$ of horseradish peroxidase, $25 \mathrm{mM}$

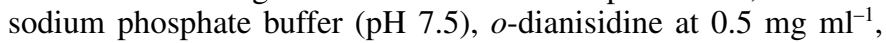
$2 \%$ Triton $\mathrm{X}-100$, and a known amount of purified Th-L-AAO $(6 \mu \mathrm{M})$ or crude extract. After $15 \mathrm{~h}$ at $37^{\circ} \mathrm{C}, \mathrm{H}_{2} \mathrm{O}_{2}$ generated by the reaction was measured by reading the absorbance at $450 \mathrm{~nm}$ on an enzyme-linked immunosorbent assay plate reader (Model 680; Bio-Rad, Hercules, CA).

The $K_{\mathrm{m}}$ and the maximum reaction rate $\left(V_{\max }\right)$ for the substrate were determined using a nonlinear least square fit of the experimental data to the Michaelis-Menten equation, using Origin 7. All experiments were performed at least three times.

Analysis of the effect of Th-L-AAO on $B$. cinerea hyphal growth. Two discs (2 $\mathrm{mm}$ in diameter) of fungal $B$. cinerea hyphae were cut from the edges of 5-day-old fungal cultures grown in PDA at $25^{\circ} \mathrm{C}$ and inoculated on the opposite sides of 9-cm-diameter PDA-coated plates. A sterile filter paper disc $(6 \mathrm{~mm})$ impregnated with the appropriate concentration of Th-L-AAO at 3,6 , or $12 \mu \mathrm{g} \mathrm{disc}{ }^{-1}$ was placed on the advancing fungal hyphae on one side, with a control disc containing sterile distilled water on the other side. The plates were further incubated at $22^{\circ} \mathrm{C}$ for 5 days. The hyphal growth was photographed and the diameters were recorded daily. The percentage of hyphal growth reduction was calculated using the formula hyphal growth reduction $(\%)=$ $\left\{\left[D_{(\mathrm{c})}-D_{(\mathrm{t})}\right] / D_{(\mathrm{c})}\right\} \times 100 \%$, where $D_{(\mathrm{c})}$ is the diameter of the growth area of $B$. cinerea hyphae on the control plate and $D_{(\mathrm{t})}$ is the diameter of the growth area of $B$. cinerea hyphae on the Th-LAAO-containing plate. The control treatment with the highest growth was compared with other Th-L-AAO treatments in a oneway analysis of variance (ANOVA). Means were separated using Tukey's honestly significant difference (HSD) test and to identify significant groupings. Statistical analyses were performed using the Statistical Software Package for the Social Sciences (version 12.0.1 for Windows; SPSS Inc., Chicago).

For light microscopy, a thin layer of PDA was spread on sterile microscope slides in the center of sterile culture plates. One disc ( $2 \mathrm{~mm}$ in diameter) of fungal B. cinerea hyphae was cut from the growing edge of 5-day-old fungal cultures and transferred to the center of the PDA-coated slides. A sterile filter paper disc impregnated with $6 \mu \mathrm{g}$ of Th-L-AAO was placed on the fungal hyphae. The glass slides were stained with lactophenol blue and observed daily under a light microscope for 3 to 4 days.

Effects of Th-L-AAO on B. cinerea-infected apple fruit and tobacco leaves. Th-L-AAO was tested for its effect on the development of $B$. cinerea on inoculated apple fruit and tobacco leaves. The postharvest apple fruit was wounded with a 7-mmdiameter cork borer, then inoculated with a 6-mm-diameter hyphal plug from a 5-day-old PDA plate of B. cinerea (28). For determining the effect of Th-L-AAO, Th-L-AAO at $30 \mu \mathrm{g} \mathrm{ml}{ }^{-1}$ was applied at the infection site prior to the inoculation of $B$. cinerea; Th-L-AAO was not applied at the infection site in the case of control treatment. The inoculated apple fruit were stored at $25^{\circ} \mathrm{C}$ in the dark. After 6 days, the lesions spreading on the surface of the apple were photographed, and the radii of the expansion zones were recorded. All experiments were performed in triplicate. One-way ANOVA was used to compare treatment groups. The $\alpha$ level of 0.05 was considered statistically significant. Tukey's HSD test was used to identify significant groupings. Statistical analyses were performed using the Statistical Software Package for the Social Sciences (version 12.0.1; SPSS Inc.) (also see experiments pertaining to tobacco leaves below).

Tobacco leaves were detached from 12-week-old plants grown in the greenhouse and inoculated with a hyphal plug of $B$. cinerea from a 5-day-old PDA-containing plate in order to examine the effects to the fungus (5). For testing the effect of Th-L-AAO on $B$. cinerea fungal pathogenesis, a sterile filter paper disc impregnated with Th-L-AAO at a concentration of $6 \mu \mathrm{g} \operatorname{disc}^{-1}$ was applied at the infection site, while a control disc impregnated with sterile distilled water was applied at the infection site. Afterward, the inoculated tobacco leaves were placed in petri plates with moist filter paper discs at $25^{\circ} \mathrm{C}$ in the dark. After 14 days of incubation, the development of $B$. cinerea was photographed. The radii of the spreading lesions were recorded and then used to evaluate disease effect in Th-L-AAO-treated leaves and untreated leaves. All experiments were performed in triplicate.

Detection of reactive oxygen species generation. To determine the apoptotic response in $B$. cinerea, we measured reactive oxygen species (ROS) generation in Th-L-AAO-treated $B$. cinerea. For determining ROS generation in cells, $B$. cinerea hyphae were loaded with $2^{\prime}, 7^{\prime}$-dichlorofluorescein diacetate $\left(\mathrm{H}_{2} \mathrm{DCF}-\mathrm{DA}\right)(21)$. After 4 days of incubation with or without Th-L-AAO $\left(6 \mu \mathrm{g} \mathrm{disc}{ }^{-1}\right)$ treatment, the hyphal portion was immersed in $1 \mu \mathrm{M} \mathrm{H}_{2}$ DCF-DA for $15 \mathrm{~min}$ after a brief rinse with distilled water, and continuously incubated for $12 \mathrm{~h}$ on a PDA plate. DCF fluorescence was visualized with a fluorescence microscope (Olympus IX70) and detected at an excitation wavelength of $485 \mathrm{~nm}$ and emission wavelength of $535 \mathrm{~nm}$ using a spectrofluorometer.

Estimation of lipid peroxidation activity. Lipid peroxidation is a consequence of ROS action on membrane structure (6) and was examined in Th-L-AAO-treated $B$. cinerea as a measure of ROS-related damage. Malondialdehyde (MDA), a major product of lipid peroxidation, was quantified to estimate the extent of lipid peroxidation in this fungus. In brief, $B$. cinerea was treated with Th-L-AAO $\left(6 \mu \mathrm{g} \mathrm{disc}^{-1}\right)$ for 4 days. B. cinerea was not treated with the Th-L-AAO in the case of control treatment. The hyphae were collected and their MDA concentrations were determined. The reaction mixture consisted of $0.125 \mathrm{ml}$ of $\mathrm{KCl}, 0.05 \mathrm{ml}$ of $8.1 \%$ sodium dodecyl sulfate (SDS), $0.375 \mathrm{ml}$ of $20 \%$ acetic acid (pH 3.5), $0.375 \mathrm{ml}$ of a $0.8 \%$ aqueous solution of thiobarbituric acid (TBA), and $0.125 \mathrm{ml}$ of hyphal homogenate. The mixture was heated at $95^{\circ} \mathrm{C}$ for $60 \mathrm{~min}$ and then cooled on ice for $15 \mathrm{~min}$. Afterward, $1 \mathrm{ml}$ of $n$-butanol and pyridine (15:1, vol/vol) was added, and the mixture was centrifuged at $4{ }^{\circ} \mathrm{C}$ for $10 \mathrm{~min}$ at $4,000 \times g$. The MDA concentration in the cell homogenate was determined using the TBA assay (33). The organic layer was separated, and its absorbance was measured at $535 \mathrm{~nm}$ using a UV-visible spectrophotometer. The mean values for three independent experiments were calculated.

DNA extraction and analysis. DNA fragmentation is a key feature of programmed cell death (18). Here, we examined the effect of Th-L-AAO on DNA damage in B. cinerea. After 5 days of incubation with or without Th-L-AAO $\left(6 \mu \mathrm{g} \mathrm{disc}{ }^{-1}\right)$ treatment, the $B$. cinerea hyphae $(0.3 \mathrm{~g})$ were frozen in liquid nitrogen and ground into a fine powder. Each hyphal sample was resuspended with $700 \mu \mathrm{l}$ of lysis buffer $(50 \mathrm{mM}$ Tris- $\mathrm{HCl}$ [pH 7.2], $1 \%$ mercaptoethanol, and $3 \%$ SDS) and then incubated at $65^{\circ} \mathrm{C}$ for 60 min with shaking every $15 \mathrm{~min}$. Next, the samples were mixed with an equal volume of chloroform and isoamyl alcohol (24:1, $\mathrm{vol} / \mathrm{vol}$ ). After gentle shaking for $5 \mathrm{~min}$, the mixture was centrifuged for $10 \mathrm{~min}$ at $12,000 \times g$. Total DNA was precipitated by the addition of $50 \mu \mathrm{l}$ of $3 \mathrm{M} \mathrm{NaOAc}$ and $500 \mu \mathrm{l}$ of 2-propanol. 
After $20 \mathrm{~min}$, the samples were centrifuged for $20 \mathrm{~min}$ at $12,000 \times g$ and washed with $200 \mu$ of $70 \%$ ice-cold ethanol. The $B$. cinerea hyphal DNA was then recovered by centrifugation for $5 \mathrm{~min}$ at $12,000 \times \mathrm{g}$, and the sample was dried under vacuum for $20 \mathrm{~min}$. The total DNA was dissolved in $50 \mu \mathrm{l}$ of TrisEDTA buffer (10 mM Tris-HCl and $0.1 \mathrm{mM}$ EDTA). For detecting DNA laddering, the samples were run on a $1 \%(\mathrm{wt} / \mathrm{vol})$ agarose gel, and the DNA in the gel was visualized and photographed under ultraviolet light after staining with $0.5 \%$ ( $\mathrm{vol} / \mathrm{vol}$ ) ethidium bromide. All experiments were performed in triplicate.
Determination of mitochondrial membrane potential. Mitochondrial transmembrane potential reduction is an early event in apoptosis (29) and mediates ROS generation in a cell. Thus, we examined the effect of Th-L-AAO treatment on the mitochondrial membrane potential in $B$. cinerea. The mitochondrial membrane potential was determined by the MitoCapture apoptosis detection kit. In normal cells, MitoCapture accumulates and aggregates in the mitochondria, giving off a bright red fluorescence. However, in apoptotic cells, MitoCapture cannot aggregate in the mitochondria because of the altered mitochondrial transmembrane potential; therefore, it remains in the cytoplasm in its monomer
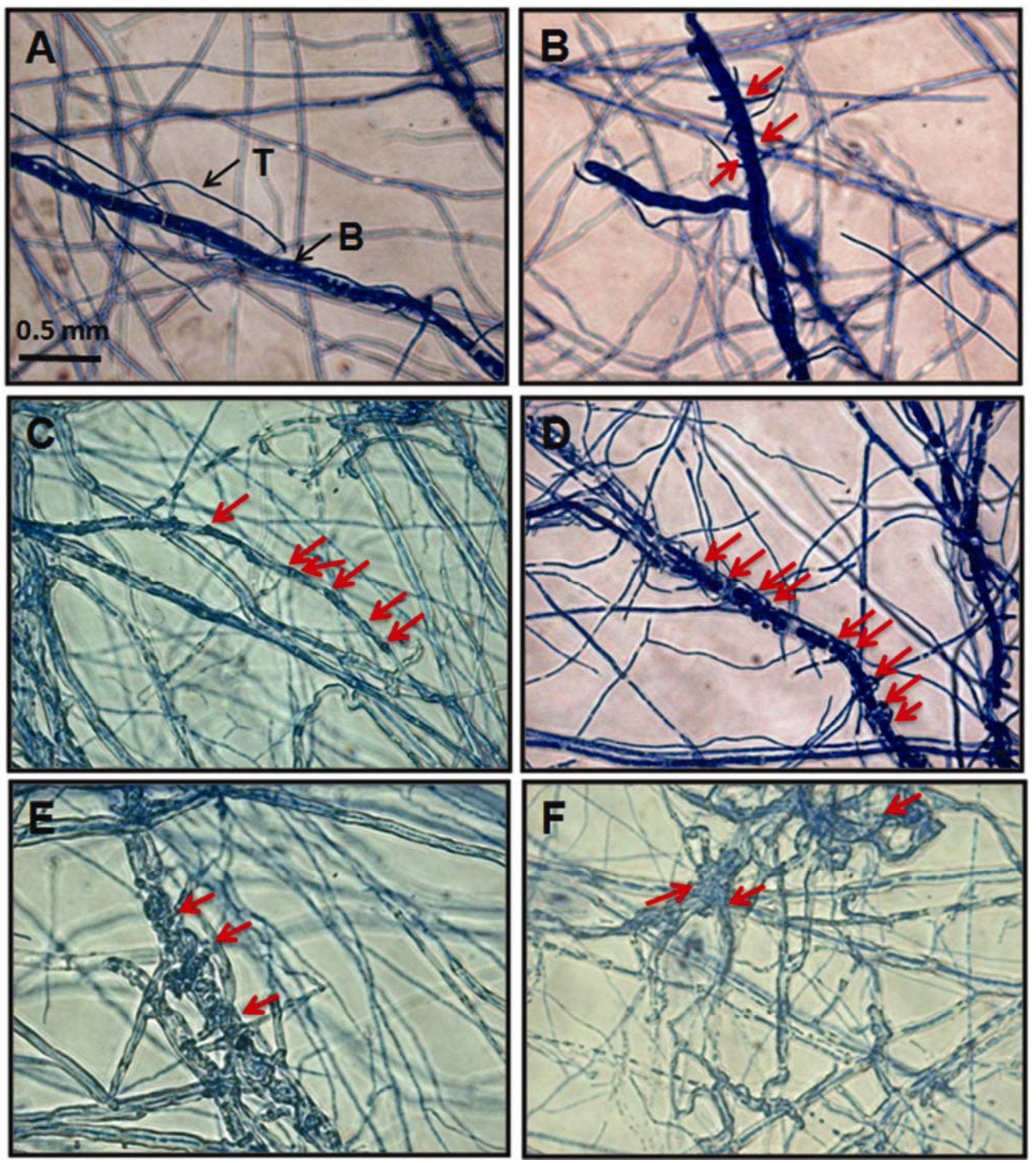

Fig. 2. Light microscopy images of the antagonism of Trichoderma harzianum ETS 323 and Botrytis cinerea co-cultured for A, 2; B, 3; C, 4; D, 5; and E and F, 6 days are shown. A, Arrows indicate T. harzianum ETS 323 hyphae contacted with $B$. cinerea hyphae. The $T$. harzianum ETS 323 hyphae (T) are thin, and $B$. cinerea hyphae (B) are rough. $\mathbf{B}, \mathbf{C}$, and $\mathbf{D}$, Arrows indicate intensive coiling on B. cinerea. $\mathbf{E}$ and $\mathbf{F}$, Arrows indicate $B$. cinerea hyphal lysis and death at 6 days. All images are at the same magnification. 
form, fluorescing green. After 3 days of incubation in medium with or without Th-L-AAO $\left(6 \mu \mathrm{g} \mathrm{disc}{ }^{-1}\right)$ treatment, the $B$. cinerea samples were incubated in the incubation buffer and MitoCapture reagent for $30 \mathrm{~min}$ at $37^{\circ} \mathrm{C}$. The cells were then collected, and the fluorescence was analyzed using a spectrophotofluorometer (Olympus IX70) at an excitation wavelength of $488 \mathrm{~nm}$ and an emission wavelength of $590 \mathrm{~nm}$.
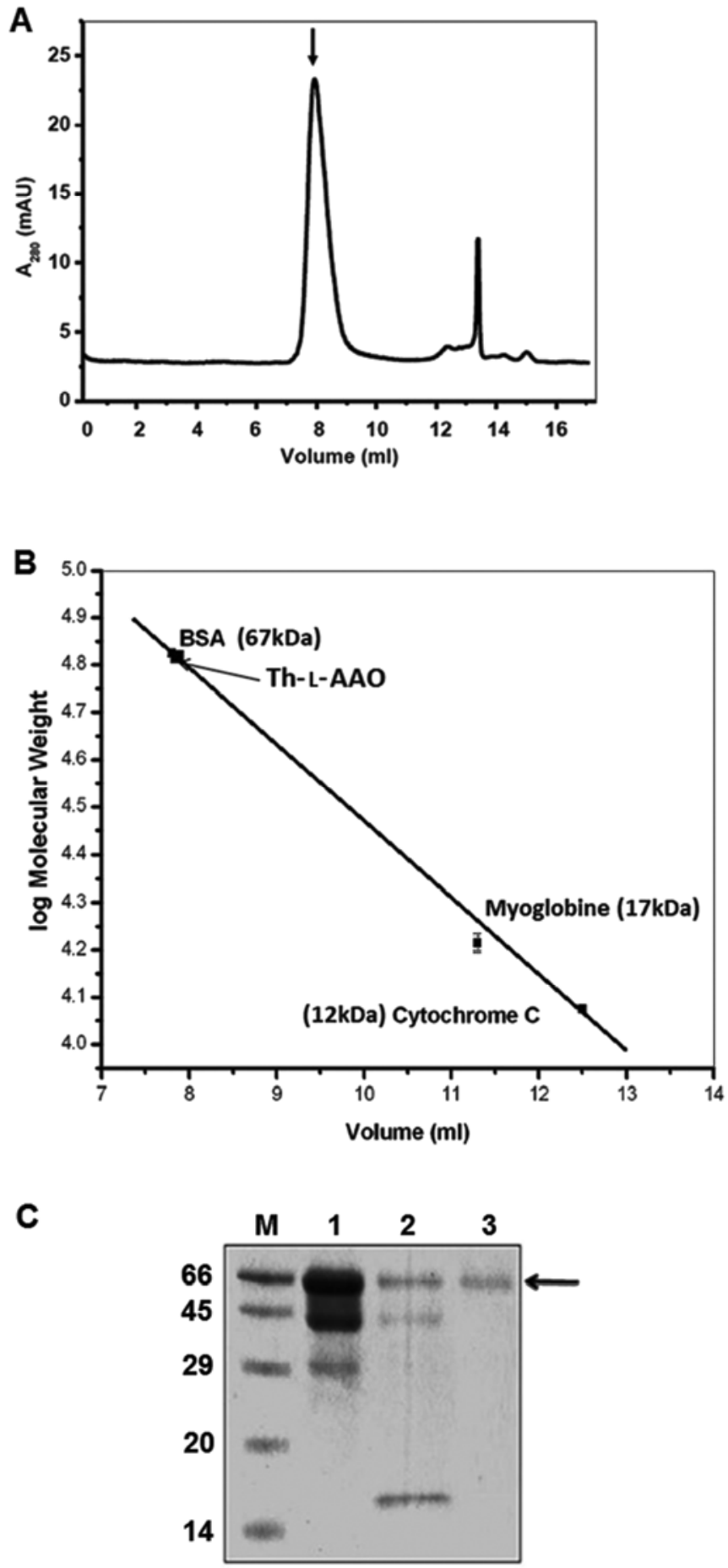

Fig. 3. A, Analytical Superdex HR 75 10/30 column gel filtration showed that Th-L-AAO elutes as a single peak; the arrow indicates the Th-L-AAO-containing fraction. B, Molecular mass of Th-L-AAO was determined to be $67 \mathrm{kDa}$. BSA $=$ bovine serum albumen. C, Purified Th-L-AAO (indicated by the arrow) from Trichoderma harzianum ETS 323 after the 10\% sodium dodecyl sulfate polyacrylamide gel electrophoresis gel was stained with Coomassie R-250. Lane M: molecular mass marker; lane 1: crude extract filtrate; lane 2: preparation after ConA-Sepharose column chromatography; lane 3: purified Th-L-AAO (67 kDa).

\section{RESULTS}

Antagonism between $T$. harzianum ETS 323 and $B$. cinerea. While growing near the $B$. cinerea hyphae, $T$. harzianum ETS 323 produced hyphal branches oriented toward the pathogenic colony (Fig. 2). After 2-3 days of co-culture, T. harzianum ETS 323 hyphae contacted and coiled with the B. cinerea hyphae (Fig. 2A and $\mathrm{B}$ ). After the fourth and fifth days of incubation, more coiling was observed, causing the cessation of $B$. cinerea hyphal growth (Fig. 2C and D). On the sixth day of incubation, hyphal lysis of $B$. cinerea was observed (Fig. 2E and F). The time-dependent coiling behavior of T. harzianum ETS 323 is shown in Figure 1.

Kinetics of coiling frequency of T. harzianum ETS 323 on $B$. cinerea hyphae. The kinetics of T. harzianum ETS 323 coiling frequency on $B$. cinerea hyphae were evaluated by biexponential equation 1b. Details of the biexponential equation are defined in the Supplemental Material provided. Here, a biphasic rate constant ( $k_{\text {obs.1 }}$ and $\left.k_{\text {obs.2 }}\right)$ for $T$. harzianum hyphal coiling was evaluated, suggesting that a two-step antagonism was involved in the mycoparasitism of $T$. harzianum against $B$. cinerea. In the first step of the antagonism, the rate constant of the hyphal coiling (fast phase, $k_{\text {obs.1 }}$ ) was found to be 1 day $^{-1}$. The amount of hyphal coiling frequency reached saturation at $27 \%$ of maximum hyphal coiling, with $F_{1}=0.27$ at $15 \mathrm{~h}$. In the second step of the antagonism, the rate constant of the hyphal coiling (slow phase, $k_{\text {obs.2 }}$ ) was observed to be 0.4 day $^{-1}$. The amount of hyphal coiling frequency was $73 \%$ of maximum hyphal coiling, with $F_{2}=0.73$. These data indicated that the rate-determining step in the mycoparasitism of $T$. harzianum ETS 323 against $B$. cinerea was step 2 , because $k_{\text {obs. } 1}$ was 2.5 -fold faster than $k_{\text {obs.2 }}$, and the mycoparasitic process of $T$. harzianum at the initial hyphal coiling stage of $T B_{1}$ reached $\approx 30 \%$ of maximum hyphal coiling.

Purification of Th-L-AAO from the culture medium of $T$. harzianum ETS 323. The putative L-AAO from the extracellular protein extracts of T. harzianum ETS 323 grown in a medium containing deactivated $B$. cinerea was purified by two steps of column chromatography (Fig. 3A and B). The protein extract was first retained on the ConA-Sepharose column and recovered in the

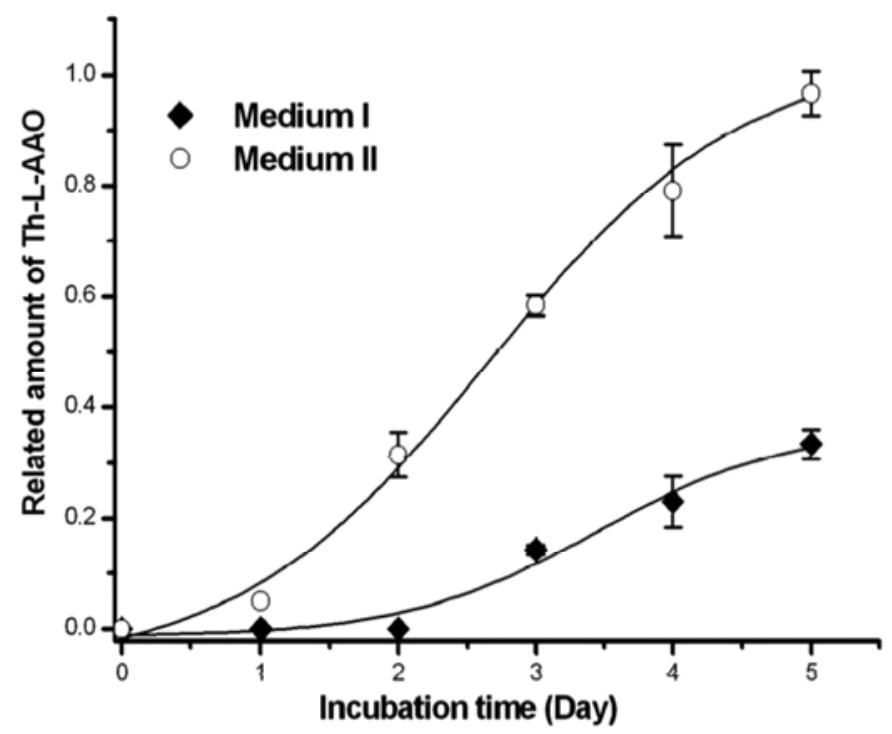

Fig. 4. For examining the effect of deactivated Botrytis cinerea hyphae on ThL-AAO secretion, the amount of Th-L-AAO secreted in $250 \mathrm{ml}$ of the culture medium over a period of 5 days was determined using $30 \mathrm{mM}$ L-phenylalanine as the substrate. $\bigcirc=T$. harzianum ETS 323 grown in the presence of deactivated $B$. cinerea hyphae (medium II). $\bullet=T$. harzianum ETS 323 grown in absence of deactivated $B$. cinerea hyphae (medium I). Values represent the means of three independent experiments, and the error bars represent the standard deviation from the mean $(n=3)$. 
mannopyranoside-eluted fraction (Fig. 3C, lane 2). Purified Th-LAAO showed a peak at the retention volume of $8.2 \mathrm{ml}$ for the culture medium in gel filtration. The SDS polyacrylamide gel electrophoresis showed that purified Th-L-AAO has a molecular mass of $67 \mathrm{kDa}$ (Fig. 3B and C, lane 3).

Substrate activity. Th-L-AAO substrate activity was tested against 17 L-amino acids, and the highest specific activity was detected with L-phenylalanine (L-Phe). The activity of purified Th-L-AAO against L-Phe and D-Phe was investigated. Th-L-AAO exhibited high activity against L-Phe as the substrate but had no detectable activity against D-Phe as the substrate. The kinetic parameters of L-Phe determined by the nonlinear least-squares fit method were $K_{\mathrm{m}}=10.7 \mathrm{mM}$ and $V_{\max }=477.4 \mu \mathrm{M} \mathrm{min}{ }^{-1}$.

Effect of deactivated $B$. cinerea hyphae on Th-L-AAO secretion by T. harzianum ETS 323. The enzyme-coupled assay was used to determine the amount of Th-L-AAO secreted by $T$. harzianum ETS 323 in the presence or absence of deactivated $B$. cinerea hyphae. The amount of Th-L-AAO secreted in the culture medium was recorded over a period of 5 days (Fig. 4). During the period between days 2 and 3, the Th-L-AAO secretion was greatly elevated when $T$. harzianum ETS 323 was grown in the presence of deactivated $B$. cinerea hyphae (medium II), as compared with when $T$. harzianum ETS 323 was grown in the absence of deactivated $B$. cinerea hyphae (medium I). After 5 days of incubation, $T$. harzianum ETS 323 exposed to the deactivated $B$. cinerea hyphae secreted a threefold amount of Th-L-AAO compared with the control, which was incubated without $B$. cinerea hyphae.
These results indicated that the amount of Th-L-AAO secreted was increased in the presence of $B$. cinerea hyphae.

Effect of Th-L-AAO on B. cinerea hyphal growth. The Th-LAAO-treated $B$. cinerea samples showed hyphal growth inhibition on PDA plates (Fig. 5). On the fourth day of incubation (Fig. 5A), lysis of the $B$. cinerea hyphae was observed after Th-L-AAO treatment, in contrast to the normal hyphal growth of controltreated B. cinerea. After the fifth day of incubation (Fig. 5B), the Th-L-AAO on the treated disc resulted in the thinning of the hyphae on the control disc, further confirming the antagonistic activity of Th-L-AAO. Various concentrations of Th-L-AAO (3, 6, and $12 \mu \mathrm{g} \mathrm{disc}{ }^{-1}$ ) were applied to the $B$. cinerea samples for 5 days and effectively inhibited $B$. cinerea, with up to $83.3 \%$ hyphal growth reduction on the fifth day of treatment (Fig. 5C). The hyphal growth of control-treated $B$. cinerea was threefold and sixfold higher than that of Th-L-AAO-treated $B$. cinerea on the fourth and fifth days of treatment, respectively.

The concentration of Th-L-AAO at $6 \mu \mathrm{g}$ disc $^{-1}$ resulted in a $75 \%$ reduction in $B$. cinerea hyphal growth and, thus, was chosen for subsequent experiments. As shown by light microscopy, the $B$. cinerea samples treated with this concentration of Th-L-AAO showed abnormal characteristics, such as the development of cytosolic vacuoles, which were not observed in the control group (Fig. 6A). Following vacuole formation (Fig. 6B), the hyphal cell wall was disrupted (Fig. 6C). Finally, lysis occurred in the abnormal B. cinerea hyphae. By contrast, the control samples showed smooth hyphal walls and intact cytosols (Fig. 6A).
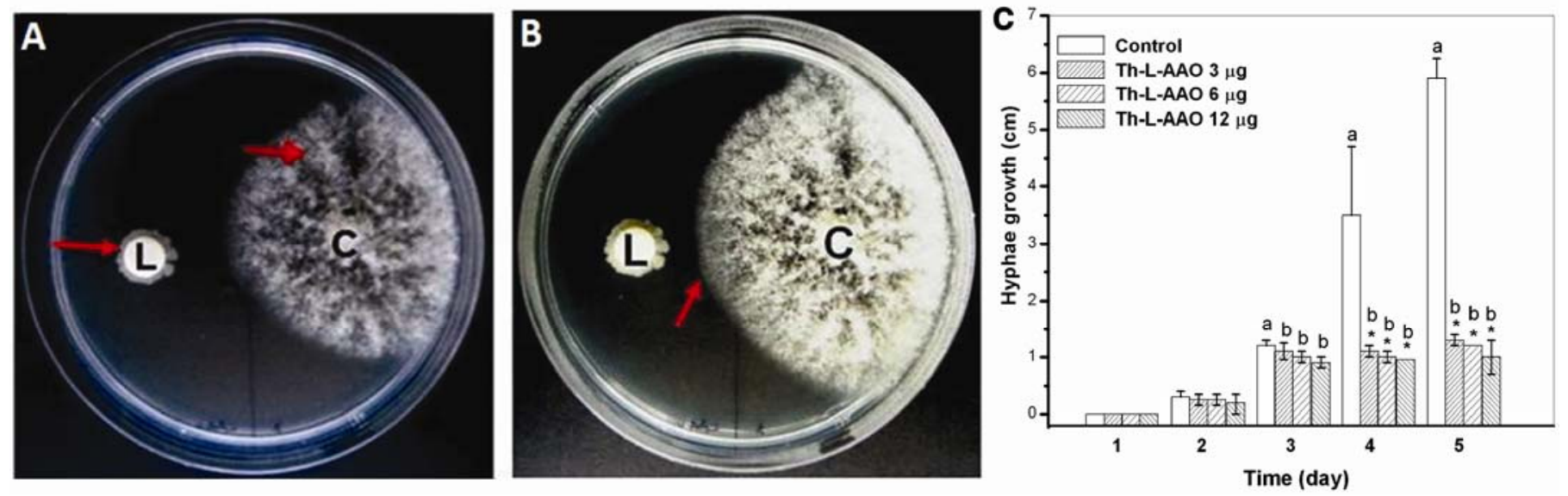

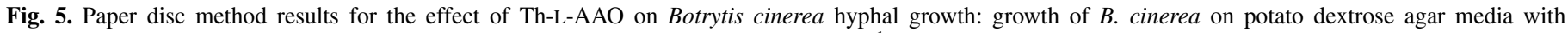

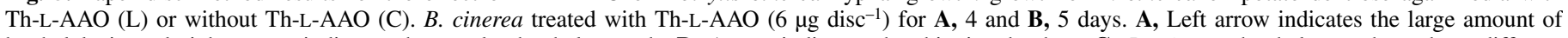

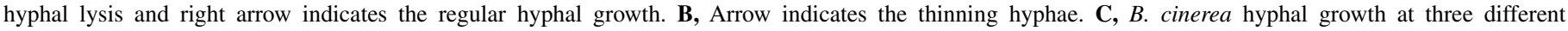

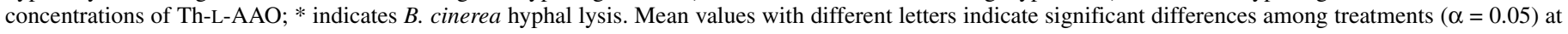

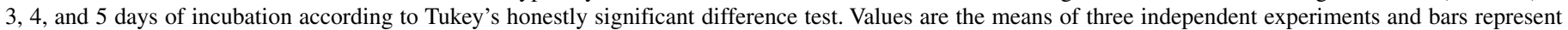
the standard deviation from the mean $(n=3)$.
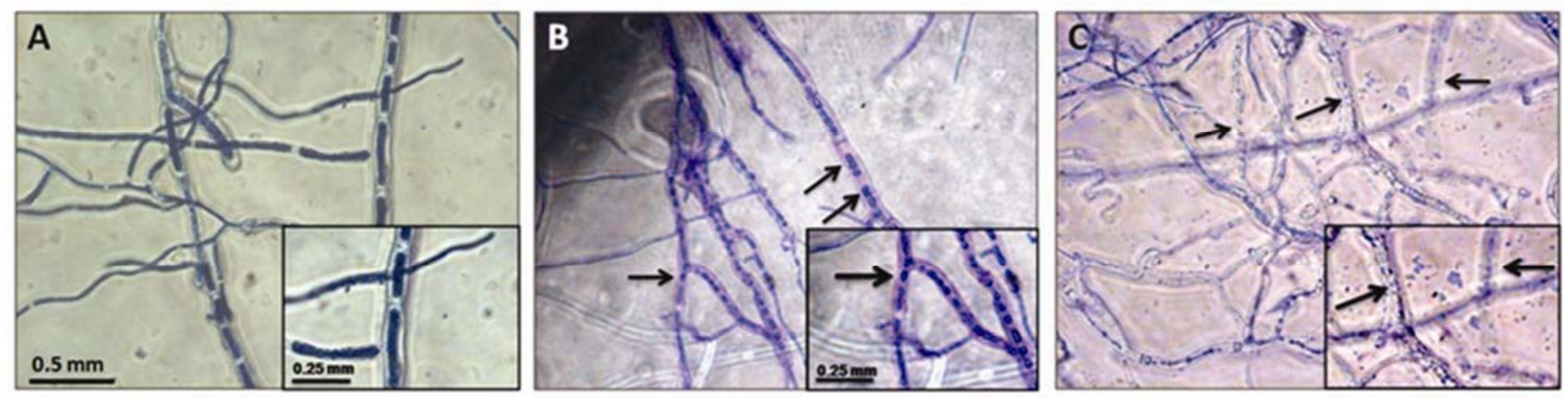

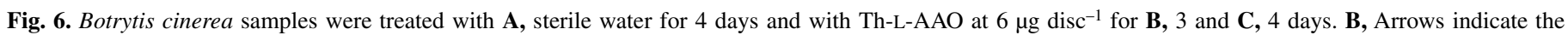
cytosolic division of $B$. cinerea after incubation with Th-L-AAO for 3 days. C, Arrow indicates a significant amount of hyphal lysis after 4 days. 
Th-L-AAO inhibits $B$. cinerea development on postharvest apple fruit and tobacco leaves. Apple fruit inoculated with $B$. cinerea and treated with Th-L-AAO showed significant inhibition of $B$. cinerea-induced lesions after 6 days (Fig. 7A), whereas untreated apple fruit exhibited development of $B$. cinerea lesions around the site of infection (Fig. 7B). The untreated apple fruit displayed a 12 -fold increase in the lesion radius relative to the treated apple fruit $(\alpha=0.05)$ (Table 1).

Th-L-AAO-treated tobacco leaves also showed enhanced inhibition to B. cinerea infections (Fig. 7C). The untreated control leaves exhibited spreading lesions around the site of infection with $B$. cinerea (Fig. 7D), whereas the leaves treated with Th-LAAO showed suppression of the lesions. The untreated tobacco leaves showed a 17-fold higher lesion radius when compared with the treated tobacco leaves $(\alpha=0.05)$ (Table 1$)$.

Th-L-AAO-induced ROS generation in $B$. cinerea. ROS generation was detected by $\mathrm{H}_{2} \mathrm{DCF}-\mathrm{DA}$. The green fluorescence increased in the Th-L-AAO-treated $B$. cinerea, indicating increased ROS generation in these hyphae (Fig. 8). The untreated $B$. cinerea showed no fluorescence throughout the 4 days of incubation (Fig. 8A). In contrast, the fluorescence was appreciable in the Th-L-AAO-treated $B$. cinerea hyphae on the second day of incubation (data not shown) and noticeable in the hyphae after 3 days (Fig. 8B). However, more hyphae were visualized with fluorescence on the third compared with the second day of incubation. On the fourth day, the Th-L-AAO-treated B. cinerea hyphae showed many green fluorescent particles, possibly representing lysates of B. cinerea (Fig. 8C).

Lipid peroxidation in Th-L-AAO-treated $B$. cinerea. The concentration of MDA, a marker of lipid peroxidation, increased in a time-dependent manner in the hyphae of $B$. cinerea after treatment with Th-L-AAO. MDA concentrations of $0.2,0.5$, and $12.5 \mu \mathrm{M}$ were observed on the second, third, and fourth days of incubation, respectively, with Th-L-AAO. Increased MDA con-
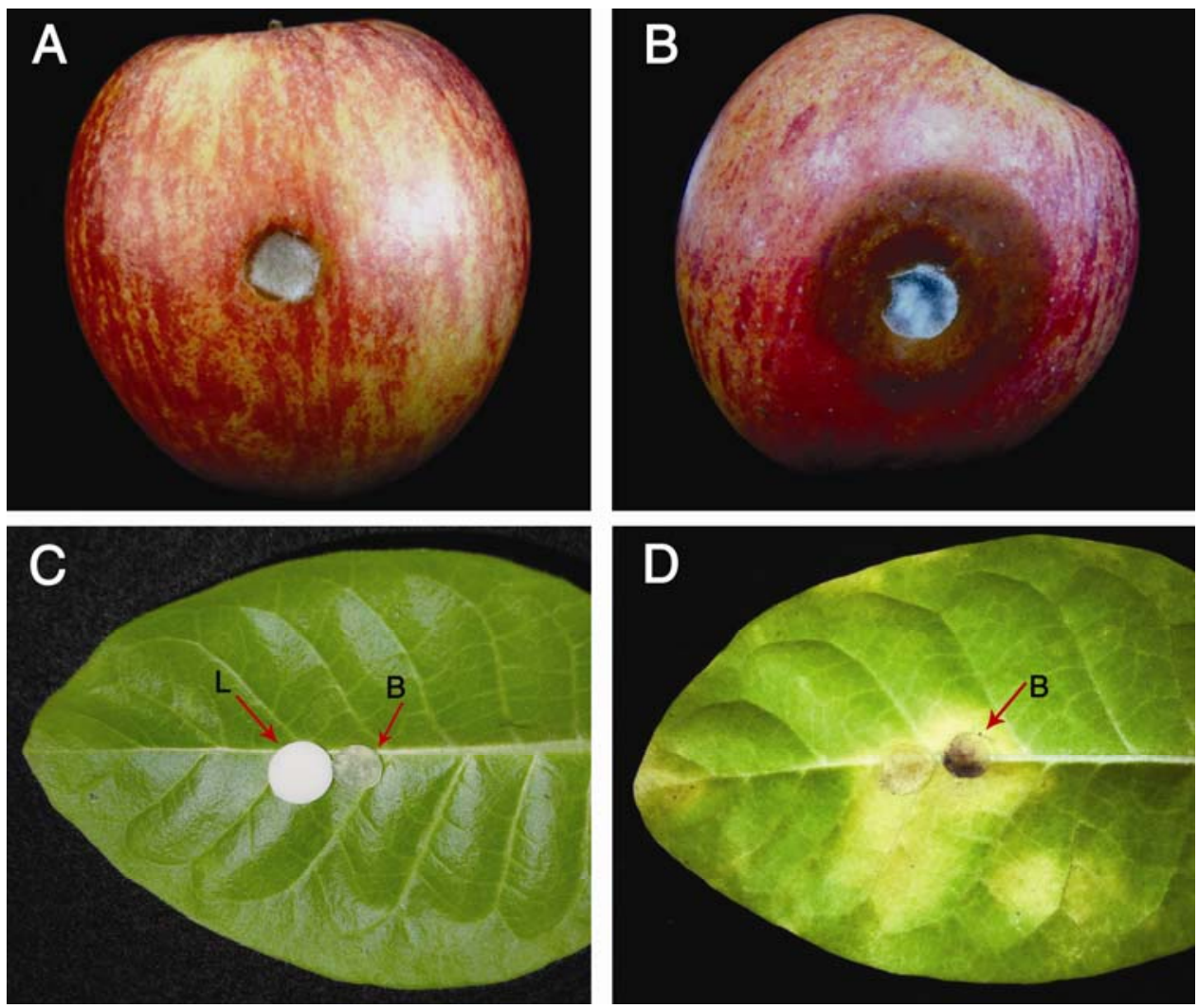

Fig. 7. Postharvest treatment of apple fruit and tobacco leaves with Botrytis cinerea. A, Th-L-AAO-treated apple fruit inoculated with the B. cinerea. B, Control (untreated) apple fruit inoculated with B. cinerea. Tobacco leaves challenged with B. cinerea and $\mathbf{C}$, treated with Th-L-AAO and $\mathbf{D}$, untreated. Arrow B indicates a plug of $B$. cinerea and arrow $\mathrm{L}$ indicates one sterile filter paper disc impregnated with Th-L-AAO.
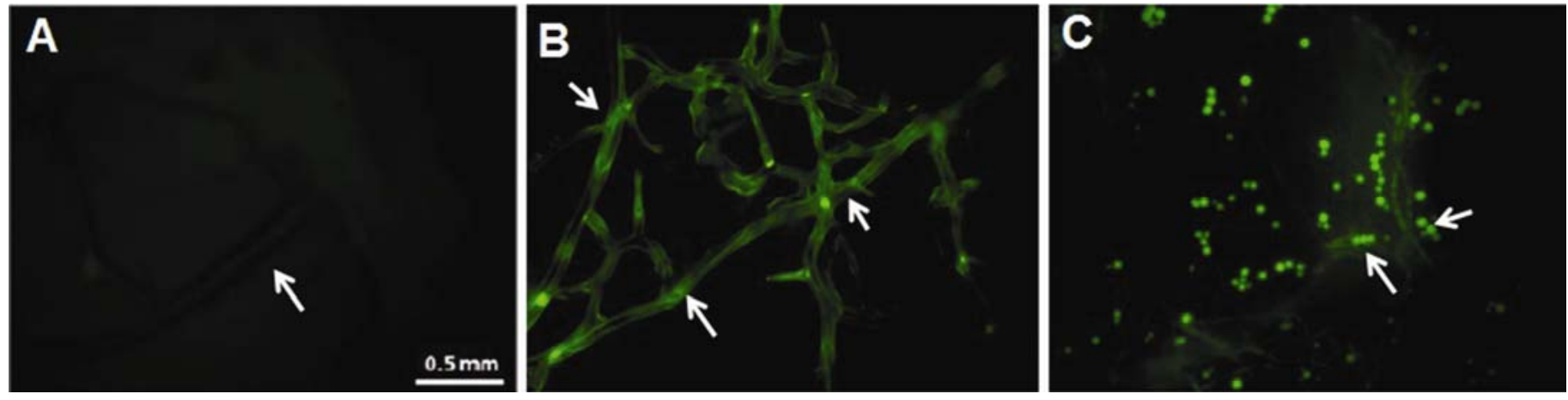

Fig. 8. A, Botrytis cinerea untreated with Th-L-AAO. B. cinerea was treated with Th-L-AAO at $6 \mu \mathrm{g} \mathrm{disc} \mathrm{c}^{-1}$ for $\mathbf{B}, 3$ and $\mathbf{C}, 4$ days. A, Arrow indicates the absence of reactive oxygen species (ROS) in $B$. cinerea hyphae. B and C, Arrows indicate the positions of representative intracellular ROS generation. All scale bars are presented in the same magnification. 
centrations were apparent in Th-L-AAO-treated B. cinerea, consistent with lipid peroxidation, whereas no MDA was observed in the control treatment (nontreated with Th-L-AAO).

DNA damage in Th-L-AAO-treated $B$. cinerea. Next, we investigated the DNA damage caused by Th-L-AAO-induced ROS stress in $B$. cinerea. DNA fragmentation of $B$. cinerea was seen only after treatment with Th-L-AAO (Fig. 9).

Effect of Th-L-AAO treatment on the mitochondrial membrane potential in B. cinerea. The mitochondria of the untreated $B$. cinerea showed red fluorescence in the MitoCapture assay, implying that the mitochondrial membrane potential remained intact (Fig. 10A). However, the green fluorescence seen in the

TABLE 1. Efficacy of the L-amino acid oxidase Th-L-AAO against infection by Botrytis cinerea in postharvest apple fruit and tobacco leaves

\begin{tabular}{lcc}
\hline & \multicolumn{2}{c}{ Radii of the lesions $(\mathrm{mm})^{\mathrm{z}}$} \\
\cline { 2 - 3 } Host & Untreated with Th-L-AAO & Treated with Th-L-AAO \\
\hline Apple fruit & $12.1 \pm 2.3 \mathrm{a}$ & $1.1 \pm 1.0 \mathrm{~b}$ \\
Tobacco leaf & $17.2 \pm 3.2 \mathrm{a}$ & $0.0 \pm 0.0 \mathrm{~b}$ \\
\hline
\end{tabular}

${ }^{\mathrm{z}}$ Radii of the lesions were measured from the edge of the inoculum plug on the surface of the fruit or leaf. Values are means \pm the standard deviation of three independent experiments. Means with the same letter are statistically equivalent according to Tukey's honestly significant difference test.

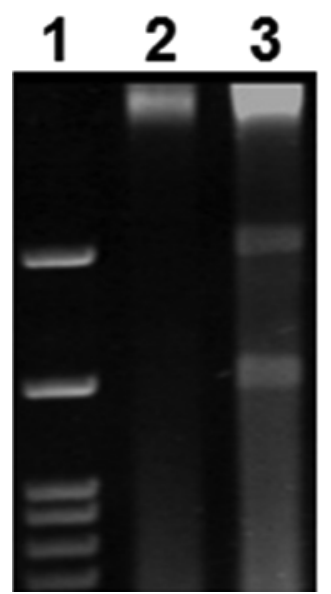

Fig. 9. DNA fragmentation of Th-L-AAO-treated Botrytis cinerea. Lane 1: molecular mass marker; lane 2: B. cinerea without 5-day Th-L-AAO treatment; lane 3: B. cinerea with 5-day Th-L-AAO treatment.
Th-L-AAO-treated B. cinerea samples (Fig. 10B) suggested depolarization of the mitochondrial membrane, as induced by ThL-AAO.

\section{DISCUSSION}

Trichoderma spp. are common biocontrol agents against fungal phytopathogens $(4,8,34,51)$. The mechanisms of their biocontrol have been found to involve various important modes of action, including mycoparasitism, antibiosis, and induction of plant resistance $(4,15,35,36,48)$. Here, we reported that the mycoparasitism of $T$. harzianum ETS 323 against $B$. cinerea occurred in the form of a two-step antagonism (hyphal coiling with a biphasic rate) under culture conditions. A possible explanation for this two-step process may lie in the observation that $T$. harzianum ETS 323 first makes contact with $B$. cinerea via less hyphal coiling $\left(F_{1}=0.27\right)$ in the fast phase $\left(k_{\text {obs.1 }}=1\right.$ day $\left.^{-1}\right)$, with the mechanism of antagonism between these two fungi being the secretion of extracellular proteins. Afterward, T. harzianum ETS 323 shows more extensive coiling $\left(F_{2}=0.73\right)$ in the slow phase $\left(k_{\text {obs. } 2}=0.4\right.$ day $\left.^{-1}\right)$, when the defense response of $B$. cinerea is blocked by the $T$. harzianum ETS 323 -secreted proteins. This may provide an explanation for the involvement of the initial hyphal coiling stage $\left(T B_{1}\right)$ in the mycoparasitism of $T$. harzianum ETS 323 against $B$. cinerea.

The mycoparasitic process of Trichoderma spp. has been reported to include two distinct classes of enzymes: cell-walldegrading enzymes and proteases $(10,11,16,24,26,42)$. The cellwall-degrading enzymes, such as chitinases (11) and glucanases (24), directly affect the integrity of the pathogen cell wall. The proteases produced by Trichoderma spp. can break down enzymes or cell wall proteins produced by certain pathogens $(10,16,26,42)$. The present study allowed for the direct observation of the Th-L-AAO-based T. harzianum ETS 323 antagonism against $B$. cinerea. The results showed cytosolic division and cytoplasmic leakage in Th-L-AAO-treated $B$. cinerea. Th-L-AAO treatment also showed direct disease control against $B$. cinerea development on postharvest apple fruit and tobacco leaves. Prior research has suggested that the mitochondria-related apoptosis in cells may cause endogenous ROS generation and result in DNA damage $(12,23,43)$. Our results indicate that Th-L-AAO treatment caused an apoptosis-like response in $B$. cinerea, as seen by depolarization of the mitochondrial membrane potential, ROS generation, DNA fragmentation, and progressive lipid peroxidation in Th-L-AAO-treated B. cinerea. These findings suggest
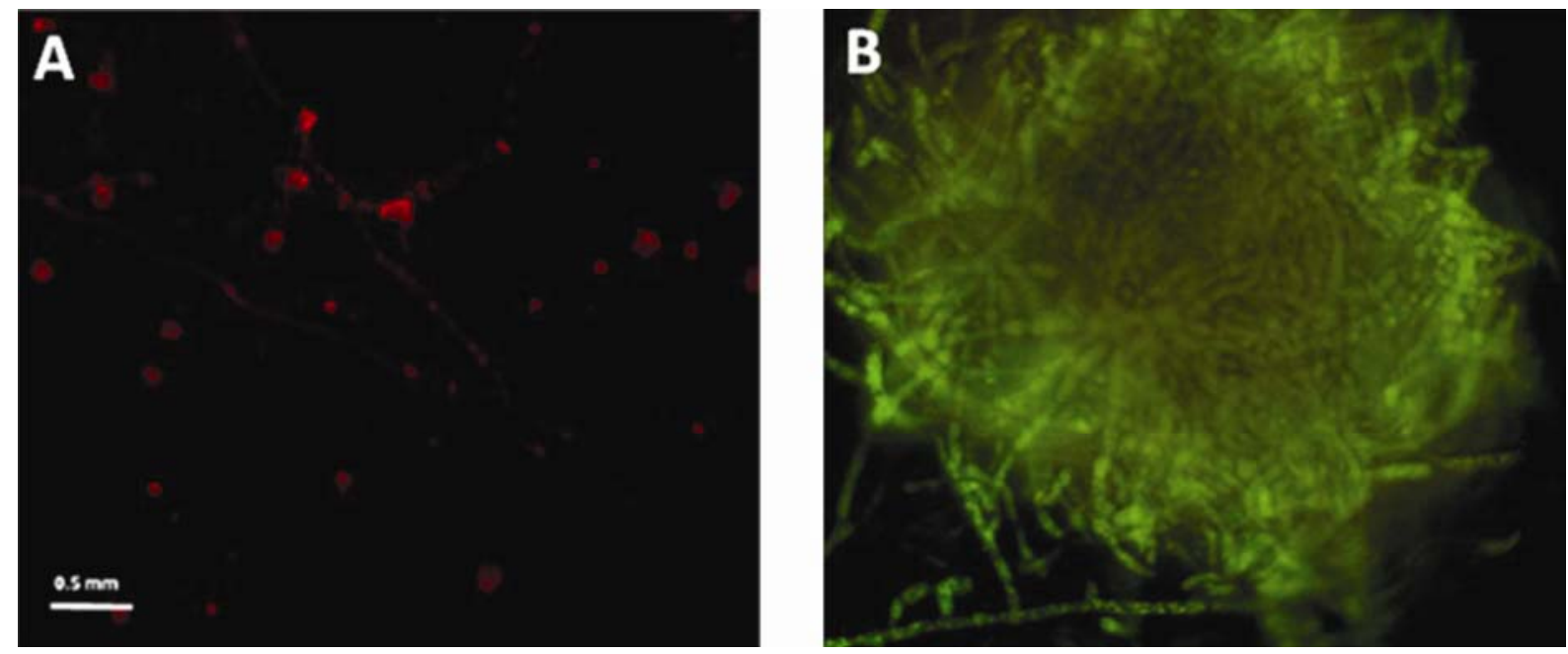

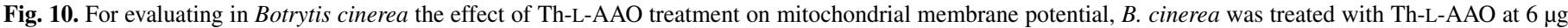

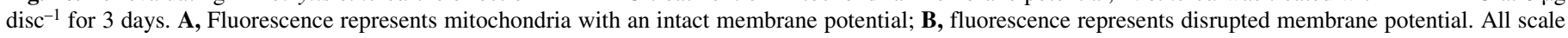
bars are presented in the same magnification. 
that the effect of Th-L-AAO on B. cinerea is very different from that of the cell-wall-degrading enzymes and proteases observed in other mycoparasitic mechanisms. As mentioned above, several lytic enzymes have been suggested to be involved in the antagonism of Trichoderma spp. $(10,11,16,24,26,50,51)$ and are capable of breaking down the cell wall components of the host pathogen. However, an L-amino acid oxidase (Th-L-AAO), a new class of enzymes related to the antagonism of Trichoderma spp. against plant pathogens (e.g., B. cinerea), was presented here and showed antagonistic activity by inducing an apoptosis response in B. cinerea.

Previous studies have shown that the secretion of Th-L-AAO was observed when $T$. harzianum ETS 323 was grown in the presence of B. cinerea (50). Our results showed that the amount of secreted Th-L-AAO increased threefold with exposure to deactivated $B$. cinerea hyphae, and that an appreciable level of ROS generation occurred in Th-L-AAO-treated $B$. cinerea during the 2 days of incubation. Taken together, these findings suggest that Th-L-AAO was secreted after hyphal contact between $T$. harzianum ETS 323 and $B$. cinerea, leading to the induction of programmed cell death in $B$. cinerea. These indications seem to agree with the model of two-step antagonism: T. harzianum ETS 323 first contacts $B$. cinerea through less hyphal coiling in the fast phase while extracellular proteins such as Th-L-AAO are secreted, and then more coiling of $T$. harzianum ETS 323 occurs in the slow phase after the defensive response of $B$. cinerea is blocked by the Th-L-AAO-induced apoptotic response. This suggests that the Th-L-AAO-induced apoptotic response might be associated with the two-step antagonism of mycoparasitism against $B$. cinerea.

In conclusion, we have reported the two-step antagonism of $T$. harzianum ETS 323 against $B$. cinerea in the process of mycoparasitism in culture. In addition, an L-amino acid oxidase (Th-L-AAO) was identified as a protein secreted by T. harzianum ETS 323 when grown in the presence of deactivated $B$. cinerea hyphae. This purified Th-L-AAO effectively prevented $B$. cinerea hyphal growth by inducing an apoptotic-like response, and this programmed cell death in B. cinerea seemed to correlate with the two-step antagonism of $T$. harzianum ETS 323 in mycoparasitic mechanisms.

\section{ACKNOWLEDGMENTS}

This work was supported by the NSC, Taiwan, under Grant NSC-992324-B-259-001. We thank Ruey-Yi Chang of Biotechnology, National Dong Hwa University, Taiwan, for technical assistance with fluorescence microscopy.

\section{LITERATURE CITED}

1. Ali, S. A., Stoeva, S., Abbasi, A., Alam, J. M., Kayed, R., Faigle, M., Neumeister, B., and Voelter, W. 2000. Isolation, structural, and functional characterization of an apoptosis-inducing L-amino acid oxidase from leafnosed viper (Eristocophis macmahoni) snake venom. Arch. Biochem. Biophys. 384:216-226.

2. Avrameas, S., and Guilbert, B. 1972. Enzyme-immunoassay for the measurement of antigens using peroxidase conjugates. Biochimie 54:837-842.

3. Bayley, P. M., Butler, F. M., Clark, D. C., Manser, E. J., and Martin, S. R. 1885. The assembly of microtubule protein in vitro. The kinetic role in microtubule elongation of oligomeric fragments containing microtubuleassociated proteins. Biochem. J. 15:439-455.

4. Benitez, T., Rincon, A. M., Limon, M. C., and Codon, A. C. 2004. Biocontrol mechanisms of Trichoderma strains. Int. Microbiol. 7:249260.

5. Bhargava, A., Osusky, M., Forward, B., Hancock, R., Kay, W., Misra, S. 2007. Expression of a polyphemusin variant in transgenic tobacco confers resistance against plant pathogenic bacteria, fungi and a virus. Plant Cell Tiss. Organ Cult. 88:301-312.

6. Boloor, T. P. A., Ramasarma, K. K., and Keywords, T. 2003. Methods for estimating lipid peroxidation: An analysis of merits and demerits. (Minireview) Indian J. Biochem. Biophys. 40:300-308.
7. Brunner, K., Zeilinger, S., Ciliento, R., Woo, S. L., Lorito, M., Kubicek, C. P., and Mach, R. L. 2005. Improvement of the fungal biocontrol agent Trichoderma atroviride to enhance both antagonism and induction of plant systemic disease resistance. Appl. Environ. Microbiol. 71:39593965.

8. Chet, I. 1987. Trichoderma: Application, mode of action and potential as a biocontrol agent of soilborne plant pathogenic fungi. Pages 137-160 in: Innovative Approaches to Plant Disease Control. Wiley, New York.

9. Coertze, S., and Holz, G. 1999. Surface colonization, penetration, and lesion formation on grapes inoculated fresh or after cold storage with single airborne conidia of Botrytis cinerea. Plant Dis. 83:917-924.

10. De Marco, J. L., and Felix, C. R. 2002. Characterization of a protease produced by a Trichoderma harzianum isolate which controls cocoa plant witches' broom disease. BMC Biochem. 3:3.

11. De Marco, J. L., Lima, L. H. C., Sousa, M. V., and Felix, C. R. 2000. A Trichoderma harzianum chitinase destroys the cell wall of the phytopathogen Crinipellis perniciosa, the causal agent of witches broom disease of cocoa. World J. Microbiol. Biotechnol. 16:383-386.

12. Denecker, G., Dooms, H., Van, L. G., Vercammen, D., Grooten, J., Fiers, W., Declercq, W., and Vandenabeele, P. 2000. Phosphatidyl serine exposure during apoptosis precedes release of cytochrome $\mathrm{c}$ and decrease in mitochondrial transmembrane potential. FEBS Lett. 465:47-52.

13. Du, X. Y., and Clemetson, K. J. 2002. Snake L-amino acid oxidases. Toxicon 40:659-665.

14. Elad, Y. 1988. Scanning electron microscopy of parasitism of Botrytis cinerea on flowers and fruits of cucumbers. Trans. Br. Mycol. Soc. 91:185-190.

15. Elad, Y. 1996. Mechanism involved in the biological control of Botrytis cinerea incited diseases. Eur. J. Plant Pathol. 102:719-732.

16. Elad, Y., and Kapat, A. 1999. Role of Trichoderma harzianum protease in the biocontrol of Botrytis cinerea. Eur. J. Plant Pathol. 105:177-189.

17. Esteban, J. A., Banerjee, A. R., and Burke, J. M. 1997. Kinetic mechanism of the hairpin ribozyme. Identification and characterization of two nonexchangeable conformations. J. Biol. Chem. 23:13629-1339.

18. Fernández, J. L., Cartelle, M., Muriel, L., Santiso, R., Tamayo, M., Goyanes, V., Gosálvez, J., and Bou, G. 2008. DNA fragmentation in microorganisms assessed in situ. Appl. Environ. Microbiol. 74:5925-5933.

19. Fourie, J. F., and Holz, G. 1995. Initial infection processes by Botrytis cinerea on nectarine and plum fruit and the development of decay. Phytopathology 85:82-87.

20. Garcia-Arenal, F., and Sagastra, E. M. 1980. Scanning electron microscopy of Botrytis cinerea penetration of bean (Phaseolus vulgaris) hypocotyls. J. Phytopathol. 99:37-42.

21. Gebhardt, R., and Fausel, M. 1997. Antioxidant and hepatoprotective effects of artichoke extracts and constituents in cultured rat hepatocytes. Toxicol. In Vitro 11:669-672.

22. Geueke, B., and Hummel, W. 2002. A new bacterial L-amino acid oxidase with a broad substrate specificity: purification and characterization. Enzyme Microb. Technol. 31:77-87.

23. Green, D. R., and Reed, J. C. 1998. Mitochondria and apoptosis. Science 281:1309-1312.

24. Harman, G. E. 2006. Overview of Mechanisms and Uses of Trichoderma spp. Phytopathology 96:190-194.

25. Harman, G. E., Howell, C. R., Viterbo, A., Chet, I., and Lorito, M. 2004. Trichoderma species-opportunistic, avirulent plant symbionts. Nat. Rev. Microbiol. 2:43-56.

26. Kapat, A., Zimand, G., and Elad, Y. 1998. Effect of two isolates of Trichoderma harzianum on the activity of hydrolytic enzymes produced by Botrytis cinerea. Physiol. Mol. Plant Pathol. 52:127-137.

27. Kommoju, P. R., Macheroux, P., and Ghisla, S. 2007. Molecular cloning, expression and purification of L-amino acid oxidase from the Malayan pit viper Calloselasma rhodostoma. Protein Expres. Purif. 52:89-95.

28. Lee, S. O., Kim, H. Y., Choi, G. J., Lee, H. B., Jang, K. S., Choi, Y. H., and Kim, J. C. 2009. Mycofumigation with Oxyporus latemarginatus EF069 for control of postharvest apple decay and Rhizoctonia root rot on moth orchid. J. Appl. Microbiol. 106:1213-1219.

29. Lin, R. J., Cheng, M. J., Huang, J. C., Lo, W. L., Yeh, Y. T., Yen, C. M., Lu, C. M., and Chen, C. Y. 2009. Cytotoxic Compounds from the Stems of Cinnamomum tenuifolium. J. Nat. Prod. 72:1816-1824.

30. Lukasheva, E. V., and Berezov, T. T. 2002. L Lysine $\alpha$ oxidase: physicochemical and biological properties. Biochemistry (Moscow) 67:1152-1158

31. Mendgen, K., and Hahn, M. 2002. Plant infection and the establishment of fungal biotrophy. Trends. Plant Sci. 7:352-356.

32. Nishizawa, T., Aldrich, C. C., and Sherman, D. H. 2005. Molecular analysis of the rebeccamycin L-amino acid oxidase from Lechevalieria aerocolonigenes ATCC 39243. J. Bacteriol. 187:2084-2092.

33. Ohkawa, H., Ohishi, N., and Yagi, K. 1979. Assay for lipid peroxides in animal tissues by thiobarbituric acid reaction. Anal. Biochem. 95:351358 . 
34. Papavizas, G. C. 1985. Trichoderma and Gliocladium: Biology, ecology and the potential for biocontrol. Annu. Rev. Phytopathol. 23:23-54.

35. Perazzolli, M., Dagostin, S., Ferrari, A., Elad, Y., and Pertot, I. 2008. Induction of systemic resistance against Plasmopara viticola in grapevine by Trichoderma harzianum $\mathrm{T} 39$ and benzothiadiazole. Biol. Control 47:228-234.

36. Reino, J. L., Guerrero, R. F., Hemandez-Galan, R., and Collado, I. G. 2008. Secondary metabolites from species of the biocontrol agent Trichoderma. Phytochem. Rev. 7:89-123.

37. Reis, H., Pfiffi, S., and Hahn, M. 2005. Molecular and functional characterization of a secreted lipase from Botrytis cinerea. Mol. Plant Pathol. 6:257-267.

38. Rijkenberg, F. H. J., DeLeeuw, G. T. N., and Verhoeff, K. 1980. Light and electron microscopy studies on the infection of tomato fruits by Botrytis cinerea. Can. J. Bot. 58:1394-1404.

39. Sakurai, Y., Takatsuka, H., Yoshioka, A., Matsui, T., Suzuki, M., Titani, K., and Fujimura, Y. 2002. Inhibition of human platelet aggregation by Lamino acid oxidase purified from Naja naja kaouthia venom. Toxicon 39:1827-1833.

40. Skarnes, R. C. 1970. 1-Amino acid oxidase, a bactericidal system. Nature 225:1072-1073.

41. Sosa-Alvarez, M., Madden, L., and Ellis, M. A. 1995. Effects of temperature and wetness duration on sporulation of Botrytis cinerea on strawberry leaf residues. Plant Dis. 79:609-615.

42. Suárez, M. B., Sanz, L., Chamorro, M. I., Rey, M., González, F. J., Llobell, A., and Monte, E. 2005. Proteomic analysis of secreted proteins from Trichoderma harzianum. Identification of a fungal cell wall-induced aspartic protease. Fungal Genet. Biol. 42:924-934.

43. Tada, Y., Mori, T., Shinogi, T., Yao, N., Takahashi, S., Betsuyaku, S., Sakamoto, M., Park, P., Nakayashiki, H., Tosa, Y., and Mayama, S. 2004.
Nitric oxide and reactive oxygen species do not elicit hypersensitive cell death but induce apoptosis in the adjacent cells during the defense response of oat. Mol. Plant-Microbe. Interact. 17:245-253.

44. Takatsuka, H., Sakurai, Y., Yoshioka, A., Kokubo, T., Usami, Y., Suzuki, M., Matsui, T., Titani, K., Yagi, H., Matsumoto, M., and Fujimura, Y. 2001. Molecular characterization of L-amino acid oxidase from Agkistrodon halys blomhoffii with special reference to platelet aggregation. Biochim. Biophys. Acta. 1544:267-277.

45. Torii, S., Yamane, K., Mashima, T., Haga, N., Yamamoto, K., Fox, J. W., Naito, M., and Tsuruo, T. 2000. Molecular cloning and functional analysis of apoxin I, a snake venom-derived apoptosis-inducing factor with Lamino acid oxidase activity. Biochemistry 39:3197-3205.

46. Vallon, O., Bulté, L., Kuras, R., Olive, J., and Wollman, F. A. 1993. Extensive accumulation of an extracellular L-amino-acid oxidase during gametogenesis of Chlamydomonas reinhardtii. Eur. J. Biochem. 215:351-360.

47. Viret, O., Keller, M., Jaudzems, V. G., and Cole, F. M. 2004. Botrytis cinerea infection of grape flowers: light and electron microscopical studies of infection sites. Phytopathology 94:850-857.

48. Viterbo, A., Ramot, O., Chemin, L., and Chet, I. 2002. Significance of lytic enzymes from Trichoderma spp. in the biocontrol of fungal plant pathogens. Antonie Leeuwenhoek 81:549-556.

49. Yang, H., Johnson, P. M., Ko, K. C., Kamio, M., Germann, M. W., Derby, C. D., and Tai, P. C. 2005. Cloning, characterization and expression of escapin, a broadly antimicrobial FAD-containing L-amino acid oxidase from the sea hare Aplysia californica. J. Exp. Biol. 208:3609-3622.

50. Yang, H. H., Yang, S. L., Peng, K. C., Lo, C. T., and Liu, S. Y. 2009. Induced proteome of Trichoderma harzianum by Botrytis cinerea. Mycol. Res. 113:924-932.

51. Zimand, G., Elad, Y., and Chet, I. 1996. Effect of Trichoderma harzianum on Botrytis cinerea pathogenicity. Phytopathology 86:1255-1260. 